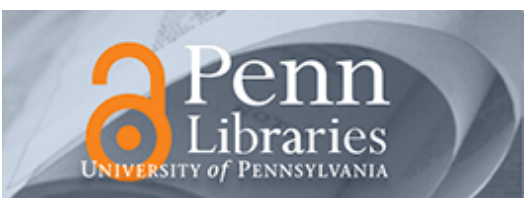

University of Pennsylvania ScholarlyCommons

November 2000

\title{
Characterizations of Lamellar Interfaces and Segregations in a PST-TiAl Intermetallic Alloy by an Analytical Scanning Transmission Electron Microscope
}

Wei (Wayne) Zhao

University of Pennsylvania

David E. Luzzi

University of Pennsylvania, luzzi@Irsm.upenn.edu

Follow this and additional works at: https://repository.upenn.edu/mse_papers

\section{Recommended Citation}

Zhao, W., \& Luzzi, D. E. (2000). Characterizations of Lamellar Interfaces and Segregations in a PST-TiAl Intermetallic Alloy by an Analytical Scanning Transmission Electron Microscope. Retrieved from https://repository.upenn.edu/mse_papers/13

Copyright Materials Research Society. Reprinted from MRS Proceedings Volume 652. 2000 Fall Meeting Symposium Y

Influences of Interface and Dislocation Behavior on Microstructure Evolution

Publisher URL: http://www.mrs.org/members/proceedings/fall2000/y/Y10_4.pdf

This paper is posted at ScholarlyCommons. https://repository.upenn.edu/mse_papers/13

For more information, please contact repository@pobox.upenn.edu. 


\title{
Characterizations of Lamellar Interfaces and Segregations in a PST-TiAl Intermetallic Alloy by an Analytical Scanning Transmission Electron Microscope
}

\author{
Abstract \\ Polysynthetically-twinned titanium aluminide (PST-TiAl), a fully lamellar $\mathrm{\gamma}-\mathrm{TiAl}+\alpha_{2}-\mathrm{Ti} 3 \mathrm{Al}$ dual-phase alloy, \\ is under evaluation for applications in rotary components in aircraft and automobile industries due to its \\ high specific strength, and a high strength-retention capability at elevated-temperatures. However, the low \\ ductility at room- to mid-high temperatures of the material hinders its application. Additions of certain \\ tertiary elements to the binary TiAl system appear to improve the ductility at room- to mid-high \\ temperatures, thus a balance among strength, ductility, and fracture toughness can be expected. In this \\ article, segregation of tertiary elements to the lamellar interfaces is investigated. Single crystals of a TiAl \\ with $0.6 \%$ atomic percentage tertiary additions are grown by an optical float-zone method. Segregation to \\ the lamellar interfaces and the microstructure of the interfaces are investigated. Structures of the \\ lamellar interfaces are characterized, and microchemistry and distribution habits of these elements along \\ the $\gamma+\alpha_{2}$ lamellar boundaries as well as the $\gamma-\gamma$ lamellar and domain boundaries are analyzed.

\section{Comments} \\ Copyright Materials Research Society. Reprinted from MRS Proceedings Volume 652. \\ 2000 Fall Meeting Symposium Y \\ Influences of Interface and Dislocation Behavior on Microstructure Evolution \\ Publisher URL: http://www.mrs.org/members/proceedings/fall2000/y/Y10_4.pdf
}




\title{
Characterizations of Lamellar Interfaces and Segregations in a PST-TiAl Intermetallic Alloy by an Analytical Scanning Transmission Electron Microscope
}

\author{
Wei (Wayne) Zhao and David E. Luzzi
}

Department of Materials Sciences and Engineering, University of Pennsylvania, 3231 Walnut Street, Philadelphia, PA 19104-6272

\begin{abstract}
Polysynthetically-twinned titanium aluminide (PST-TiAl), a fully lamellar $\gamma-\mathrm{TiAl}+\alpha_{2^{-}}$ $\mathrm{Ti}_{3} \mathrm{Al}$ dual-phase alloy, is under evaluation for applications in rotary components in aircraft and automobile industries due to its high specific strength, and a high strength-retention capability at elevated-temperatures. However, the low ductility at room- to mid-high temperatures of the material hinders its application. Additions of certain tertiary elements to the binary TiAl system appear to improve the ductility at room- to mid-high temperatures, thus a balance among strength, ductility, and fracture toughness can be expected. In this article, segregation of tertiary elements to the lamellar interfaces is investigated. Single crystals of a TiAl with $0.6 \%$ atomic percentage tertiary additions are grown by an optical float-zone method. Segregation to the lamellar interfaces and the microstructure of the interfaces are investigated. Structures of the lamellar interfaces are characterized, and microchemistry and distribution habits of these elements along the $\gamma+\alpha_{2}$ lamellar boundaries as well as the $\gamma-\gamma$ lamellar and domain boundaries are analyzed.
\end{abstract}

\section{INTRODUCTION}

Polysynthetically-twinned titanium aluminide (PST-TiAl) single crystals comprised of lamellar $\mathrm{TiAl}$ and $\mathrm{Ti}_{3} \mathrm{Al}$ provide the opportunity to distinguish the behavior of the two phases and the different lamellar interfaces. The near coherency of the lamellar interfaces allows direct imaging of the interface atomic structure with the atomic-level flatness enabling high-resolution studies of the segregation of tertiary elements. With precise crystal lattice relationships maintained over macroscopic distances, crystal orientation effects on properties can be studied. At the present time, little is known about the segregation properties of the different lamellar interfaces in TiAl alloys, and almost nothing is known about the effects of the segregation on the strength and deformation behavior of these lamellar interfaces. This article reports the partitioning habit of tertiary elements in the PST TiAl alloy with lamellar structures. The results presented here are important to understand the relationships between atomic structure, segregation and strength at $\gamma-\gamma$ and $\alpha_{2}-\gamma$ interfaces in polysynthetically twinned (PST) TiAl containing ternary alloying additions. 


\section{EXPERIMENTS}

Both binary and ternary alloys were prepared by arc-melting using a non-consumable tungsten electrode. One of the elements $\mathrm{W}, \mathrm{Ta}, \mathrm{Cu}$, or $\mathrm{Mo}$, was added to each ternary alloy. The nominal composition of the binary alloy was Ti-49.3 at.\%-Al. Tertiary additions of 0.6 at.\% were used to facilitate the growth of the PST single crystals. This addition replaced the Ti and $\mathrm{Al}$ in equal measure producing ternary alloy compositions of Ti-49 at.\% $\mathrm{Al}-0.6$ at.\% X.

The PST crystals were grown from master ingots using an ASGAL FZ-SS35W optical floating-zone furnace at a growth rate of less than $5 \mathrm{~mm} / \mathrm{h}$ under an Ar gas flow. Growth rates as slow as $2.5 \mathrm{~mm} / \mathrm{h}$ were necessary in order to obtain PST single crystals of some of the ternary alloys. All crystals have a lamellar structure. The crystals contain about $5 \%$ of the $\mathrm{Ti}_{3} \mathrm{Al}_{2} \alpha_{2}$ phase in a matrix of lamellar TiAl $\gamma$ phase.

Crystal orientations were determined using a Back-Laue X-ray diffractometer, and sometimes, reconfirmed by RIGAKU x-ray diffraction spectra to identify the required preferred crystal orientations. Specimens with dimensions $5 \times 5 \times 0.5 \mathrm{~mm}^{3}$ were machined from the oriented PST crystals by an electric spark discharge machine. The lamellar structure is composed of $\gamma$ $\mathrm{TiAl}$ and $\alpha_{2} \mathrm{Ti}_{3} \mathrm{Al}$ lamellae with orientation relationships of $\{111\}_{\gamma} \|(0001)_{\alpha 2}$ and $\langle 110]_{\gamma} \|\langle 1120\rangle_{\alpha 2}$; the lamellar boundaries are parallel to (111) $\gamma$. Slices were machined with the normal to the thin dimension parallel to the $\gamma\langle 111\rangle,\langle 110\rangle$ and $\langle 112\rangle$ directions, i.e., parallel or normal to the lamellar boundaries. Mechanically polished TEM $3 \mathrm{~mm}-\phi$ discs were machined using an ultrasonic disc cutter from the as-polished PST-TiAl samples. TEM thin foils were prepared by electropolishing to perforation using a Tenupol-3 twin-jet electropolisher at $20 \mathrm{~V}$ and $-30{ }^{\circ} \mathrm{C}$ with a solution consisting of $6 \%$ perchloric acid and $35 \%$ butyl alcohol in $59 \%$ methanol. The foils were examined in a Philips 420 TEM operating at $120 \mathrm{kV}$ to determine quality and to examine crystallographic and microstructural features. A JEOL-2010F field emission scanning TEM (FE-STEM) operating at $200 \mathrm{kV}$ was used for advanced observations and chemical analysis. A Princeton Gamma Tech energy dispersive x-ray fluorescence spectrometer (EDS) equipped with a $60 \mathrm{~mm}^{2} \mathrm{SiLi}$ detector was used to determine the distribution of $\mathrm{Ti}, \mathrm{Al}$ and the ternary element additions in the specimens.

\section{RESULTS AND DISCUSSIONS}

Ternary alloying of Ti-Al at the compositions of this study is a counter-indicator for successful single crystal growth. Nevertheless, with careful attention to shape of seed and feed rods, alignment, cleanliness of the material and the surrounding quartz tube, and a high-purity, oxygen-and nitrigen-gettered inert flowing gas environment, single crystals were obtained for all ternary systems in this paper. In some systems, it was necessary to reduce the growth rate at the start of the growth process, with a gradual increase after the first crystal was formed. Frequent monitoring of the power level of the furnace and careful adjustment was necessary to achieve successful growth. 

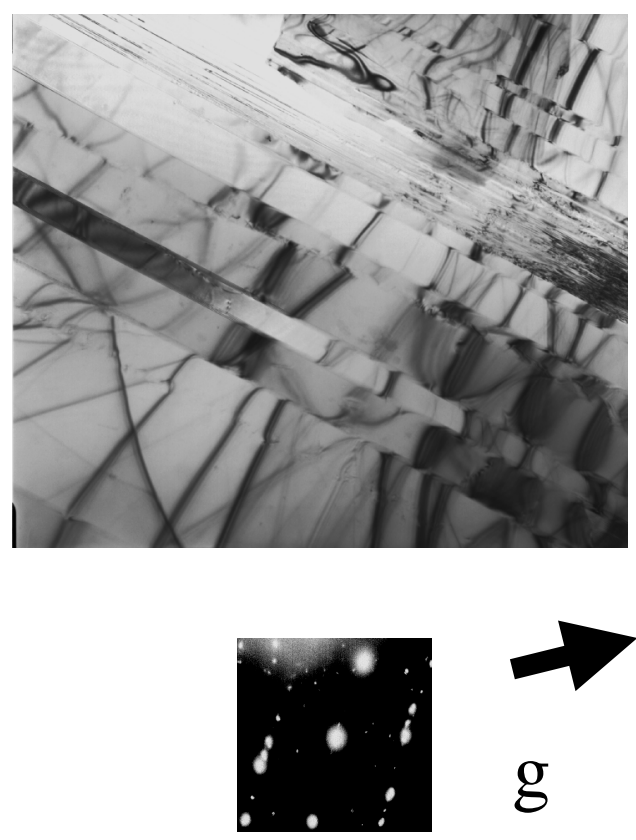
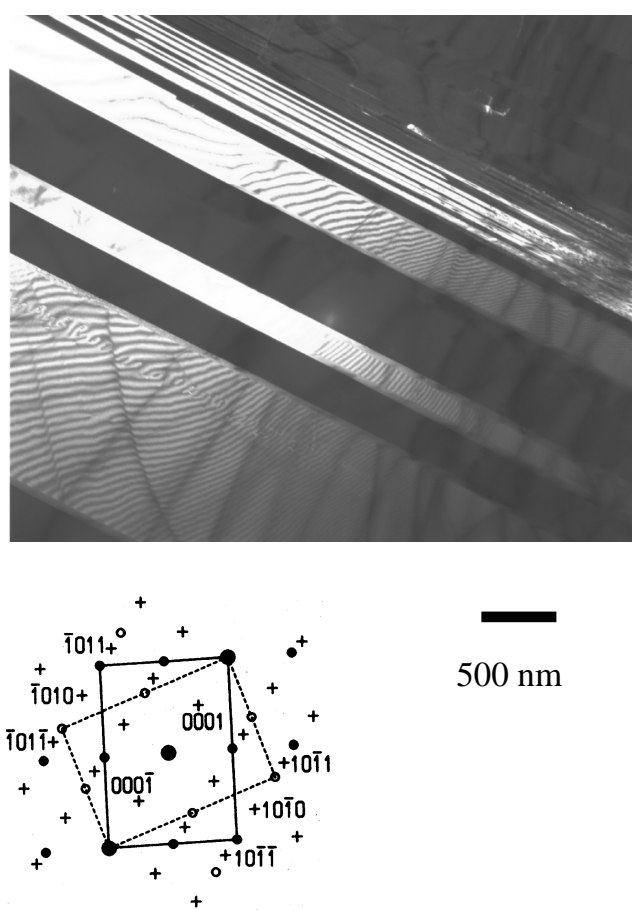

$500 \mathrm{~nm}$

Figure 1. A bright field image (left) and a g-3g weak-beam image (right) for a PST-TiAl+Mo single crystal showing the hcp $\alpha_{2}\left(\mathrm{Ti}_{3} \mathrm{Al}\right)$ lamellae and the twin-related lamellar boundaries of fct $\gamma-\gamma($ TiAl), beam // [1-10].

In Figure 1, bright-field and corresponding g-3g weak-beam TEM images of the microstructure of the ternary alloy Ti-Al-Mo are shown. The electron beam is oriented parallel to the lamellar interfaces along the $[1 \overline{1} 0]_{\gamma}$ crystal direction. The bright field and weak-beam show complementary contrast that differentiates the hcp $\alpha_{2}\left(\mathrm{Ti}_{3} \mathrm{Al}\right)$ lamellae from the twinrelated lamellae of the primitive tetragonal $\gamma-\gamma(\mathrm{TiAl})$. The superlattice diffraction pattern from the region is an overlapping of those due to the twin-related tetragonal $\gamma$ and hexagonal $\alpha_{2}$ phases; the diffraction spots of the hexagonal $\mathrm{DO}_{19}$ lattice are marked as + . It is apparent that PST-TiAl still preserves the lamellar structure with 0.6 at. \% addition of Mo. It is known that Mo will segregate to $\gamma-\gamma$ interfaces ${ }^{1}$. The atomic number of Mo is relatively high compared to Ti and Al (42 versus 22 and 13, respectively). This is important for the high-resolution TEM (HR-TEM) experiments in which the differences in atomic number facilitate the determination of the interface atomic structure. However, the segregation of Mo is at the same time very interesting from the prospective of general theoretical comprehension of driving forces for segregation. Its atomic size is smaller than that of $\mathrm{Ti}$ and $\mathrm{Al}$. Therefore, its segregation to interfaces cannot be explained by the standard model in which the segregation propensity is controlled by the atomic size and the increase of the atomic volume at the interface makes the segregation favorable. This is a topic that is worthy of further investigation.

TEM micrographs of the lamellar interfaces taken at orientations away from the edge-on configuration were used to study the dislocation structure at the interfaces. This analysis showed 
the existence of arrays of dislocations in the ternary alloys. Analysis of these dislocations indicated that they are screw dislocations. This result is consistent with the result of Kad and Hazzledine (1992) who analyzed the misfit dislocation arrays in binary alloys by weak beam microscopy and concluded that they are composed solely of screw dislocations ${ }^{2}$. These misfit dislocations could function as possible preferred sites for interfacial segregation.

Figures 2 and 3 show FE-STEM results from the ternary Ti-Al-W system. In Figure 2, a set of elemental distributions ( $\mathrm{Ti}, \mathrm{Al}, \mathrm{W}$, and $\mathrm{C}, \mathrm{N}$, and $\mathrm{O}$ ) obtained using STEM EDXS chemical mapping in a lamella region is shown. The sample is a single crystal of $\mathrm{TiAl}+\mathrm{W},(\mathrm{Al} 49.0 \%+\mathrm{W}$ $0.6 \%$ at.). The image at the bottom left is a STEM bright field image that should be dark in the regions of higher atomic number. This is confirmed by comparing the elemental maps of Ti and $\mathrm{Al}$, which show complementary contrast modulation differentiating the lamellae of $\alpha_{2}-\mathrm{Ti}_{3} \mathrm{Al}$ and $\gamma$-TiAl. The region of the specimen was chosen to contain similar amounts of each phase. Maps of $\mathrm{C}, \mathrm{N}$, and $\mathrm{O}$ indicate overall low levels of contamination consistent with surface adsorption; the small evidence of contrast modulation in these maps is due to their proximity to the low energy peak of Ti. In contrast, the $\mathrm{W}$ map indicates a strong segregation of $\mathrm{W}$ to the $\mathrm{Ti}_{3} \mathrm{Al}$ phase.

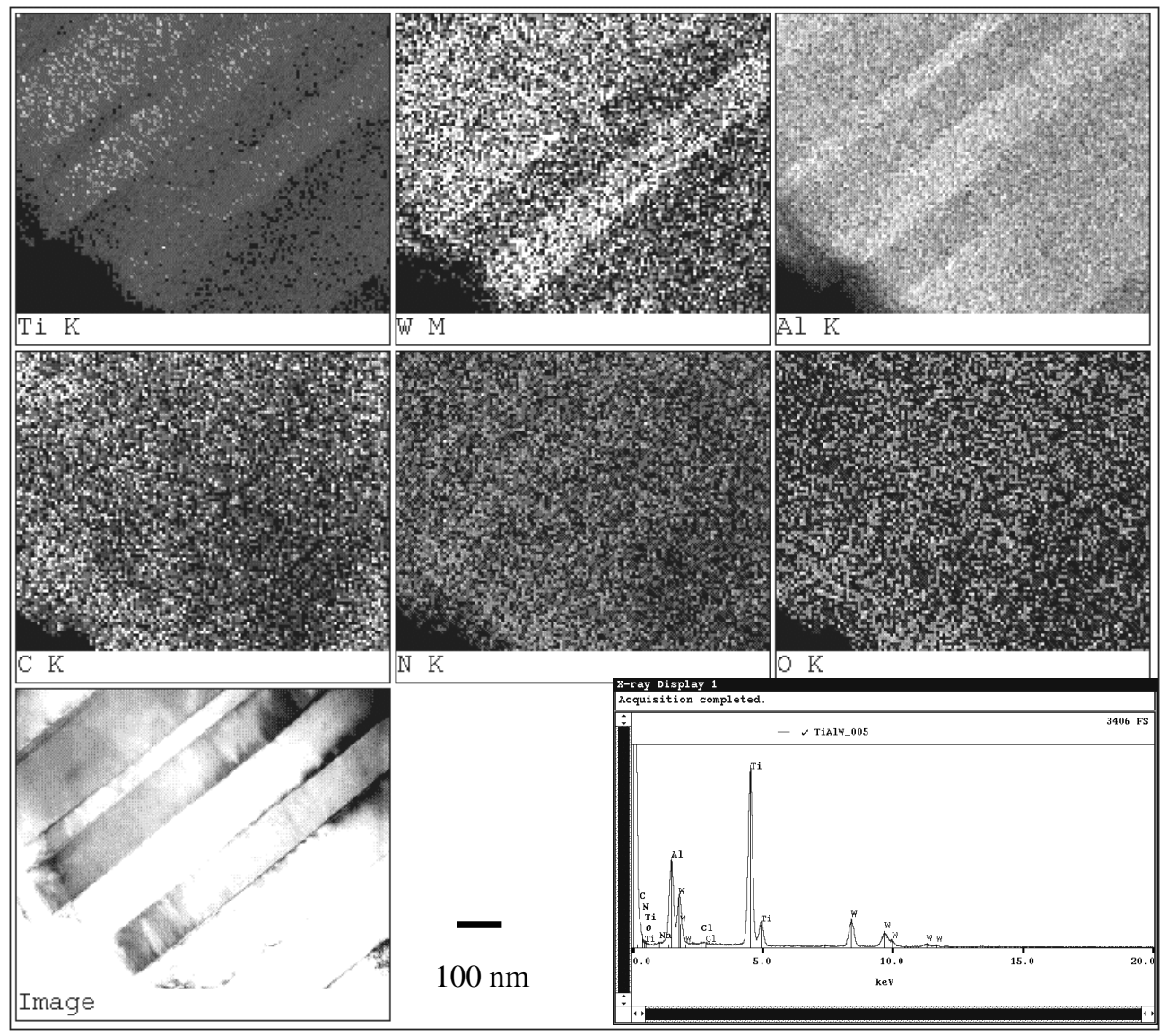

Figure 2. Elemental distributions (Ti, Al, W, and C, N, and O) by STEM EDXS Elemental Mapping in a lamella region (a single crystal of TiAl+W, Ti 50.4\% $+\mathrm{Al} 49.0 \%+\mathrm{W} 0.6 \%$ at.) 
In Figure 3, the strong segregation property of $\mathrm{W}$ is revealed in more detail. $\mathrm{W}$ concentrates in $\alpha_{2}-\mathrm{Ti}_{3} \mathrm{Al}$ lamellae and an accumulation of $\mathrm{W}$ is seen at $\gamma$-TiAl lamellar boundaries. At the lower right of the figures, a precipitate is seen to have formed along a $\gamma / \gamma$ lamellar boundary. This boundary and the precipitate are seen to be rich in $\mathrm{W}$ and Ti with the precipitate showing strong $\mathrm{W}$ contrast. Thus it appears that excess $\mathrm{W}$ has segregated to a $\gamma / \gamma$ lamellar boundary, perhaps forming a thin layer of the $\alpha_{2}$ phase. On the same boundary, a W-rich precipitate has formed.

Ternary $\mathrm{W}$ additions are known to provide the most significant increase in oxidation resistance and strength ${ }^{3}$ and to improve creep resistance ${ }^{4}, 5$, but also to lower room-temperature ductility ${ }^{5}$ in polycrystalline TiAl materials. Moreover, the brittle-ductile transition (BDT) observed at $\sim 650^{\circ} \mathrm{C}$ for most near $\gamma$-TiAl compositions is much less pronounced when $\mathrm{W}$ is present $^{5,6}$, possibly because $\mathrm{W}$ solute impedes elevated temperature dislocation movement ${ }^{6}$. Consequently, TiAl+W exhibits lower ductility at elevated temperature than other near $\gamma$-TiAl compositions. For the PST-TiAl under current investigations with a near stoichiometric composition, $95 \%$ of the lamellae are TiAl while $5 \%$ are $\mathrm{Ti}_{3} \mathrm{Al}$. Even if the solubility of $\mathrm{W}$ is higher in $\mathrm{Ti}_{3} \mathrm{Al}$ than in $\mathrm{TiAl}$, the small amount of $\mathrm{W}$ that is beyond the solubility limit of $\mathrm{W}$ in $\mathrm{Ti}_{3} \mathrm{Al}$ could preferably segregate on the TiAl-TiAl boundaries, accumulate and then precipitate along the boundaries. These precipitates may serve to impede the processes, such as twinning and dislocation glide, that contribute to ductility in these alloys.
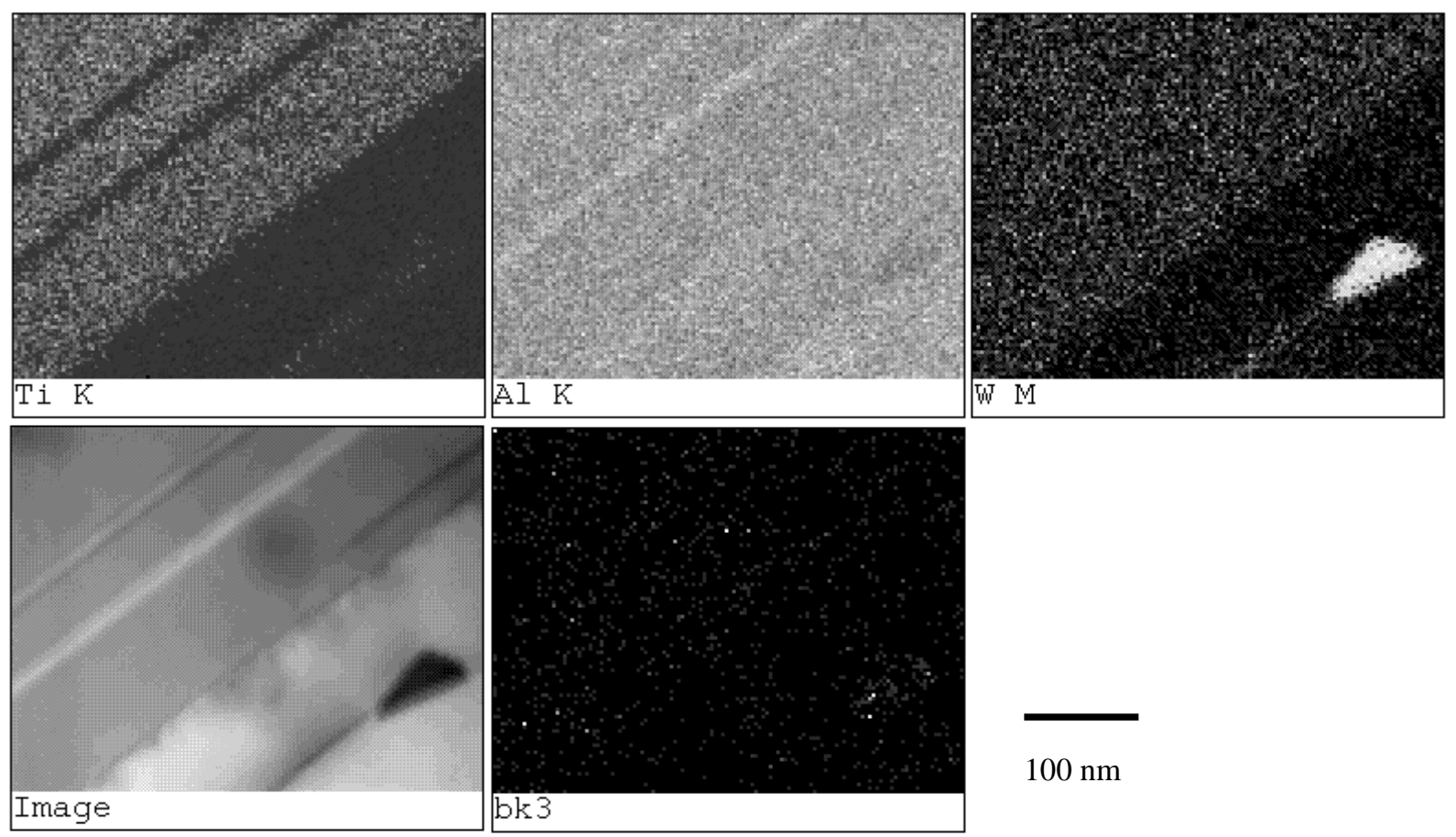

$100 \mathrm{~nm}$

Figure 3. Distribution of $\mathrm{W}$ in $\alpha_{2}-\mathrm{Ti}_{3} \mathrm{Al}$ lamellae and accumulation of $\mathrm{W}$ at the interface of $\gamma$-TiAl (STEM EDXS for a single crystal of Ti $50.4 \%+\mathrm{Al} 49.0 \%+\mathrm{W} 0.6 \%$ at.) 
In the other ternary systems studied, it was found that Ta was uniformly distributed in both the $\mathrm{Ti}_{3} \mathrm{Al}$ phase and in the TiAl phase. Similarly, STEM XEDS mappings on TiAl with Mo displayed a similar trend, with some segregation of the Mo to the lamellar boundaries. For the case of $\mathrm{Cu}$, it was found that the distribution of $\mathrm{Cu}$ is quite different from the others studied in the paper. $\mathrm{Cu}$ was found to be rich in regions coincident with excess Ti. However, at the same locations, $\mathrm{Al}$ was found to be significantly depleted, much below the level expected in $\mathrm{Ti}_{3} \mathrm{Al}$. It is possible that the $\mathrm{Cu}$ may react with $\mathrm{Ti}$ to form an intermetallic compound, of which there are several with high heats of formation within the $\mathrm{Cu}$-Ti alloy system. Existing mechanical testing data indicate that 1 at $\% \mathrm{Cu}$ additions slightly improves the strength and ductility of polycrystalline $\mathrm{TiAl}$ at 873 and $1073 \mathrm{~K}$, but at higher concentrations (2-3 at.\%), decreases the fracture strength and strain additions. This was reported to be due to embrittlement due to a second phase and grain coarsening ${ }^{7}$. Due to page limit, these XEDS elemental maps are not displayed here.

\section{SUMMARY}

Segregations/Distributions of $\mathrm{W}, \mathrm{Ta}, \mathrm{Mo}$, and $\mathrm{Cu}$, in the PST-TiAl lamellar structures, were investigated by an analytical STEM and its EDXS elemental mapping technique. The results indicate that $\mathrm{W}$ is associated with $\mathrm{Ti}$, both in the $\mathrm{Ti}_{3} \mathrm{Al}$ phase and in precipitates formed at the lamellar boundaries of the PST-TiAl phase; Ta and Mo appear to uniformly partitioned among the $\mathrm{Ti}_{3} \mathrm{Al}$ and $\mathrm{TiAl}$ phases; $\mathrm{Cu}$ forms precipitates scattered within the TiAl phase and at TiAl domain boundaries.

\section{ACKNOWLEDGMENT/DISCLAIMER}

This work was sponsored (in part) by the Air Force Office of Scientific Research, USAF, under grant/contract number F49620-99-1-0167 with Dr. Craig Hartley as the Program Manager. The views and conclusions contained herein are those of the authors and should not be interpreted as necessarily representing the official policies or endorsements, either expressed or implied, of the Air Force Office of Scientific Research or the U.S. Government. W. Zhao would like to thank Dr. Douglas Yates of University of Pennsylvania for his instruction on operation of a JEOL 2010F analytical STEM, and Mr. William Romanov, Dr. W. Kim, Ms. L. Pan, and Ms. Y. Chen, for their instructions on operation of the FZ-SS35WV ASGAL Floating Zone furnace.

\section{REFERENCES}

1 H. Inui, K. Kishida, M. Kobayashi, et al., Philosophical Magazine A 74, 451 (1996).

2 B. K. Kad and P. M. Hazzledine, Philosophical Magazine Letters 66, 133 (1992).

3 P. Martin, (Wright Laboratory, 1991).

4 Y.-W. Kim, J of Metals 41, 24 (1989).

5 P. L. Martin and H. A. Lipsitt, (Institute of Metals, London, 1990), p. 255.

6 J. Beddoes, L. Zhao, and W. Wallace, , edited by F. H. Froes, W. Wallace, R. A. Cull and E. Struckholt, 1992), p. M657.

7 T. Kawabata, H. Fukai, and O. Izumi, Acta. Mater. 46, 2185 (1998). 